\title{
Effects of Water-loading Weight Loss on the Physiological Response in College Wrestlers
}

\author{
Jinkyung $\mathrm{Cho}^{1} \mathrm{PhD}$, Taekyung $\mathrm{Han}^{2} \mathrm{PhD}$ \\ ${ }^{1}$ Institute of Sports \& Arts Convergence (ISAC), Inha University, Incheon; '2Department of Physical Education, Andong National University, Andong, Korea
}

PURPOSE: The purpose of this study was to evaluate the effects of water-loading weight loss on physiologic response.

METHODS: Thirteen consenting university wrestlers (weight $71.5 \pm 8.0 \mathrm{~kg}$, BMI $25.0 \pm 2.0 \mathrm{~kg} / \mathrm{m}^{2}$ ) randomly divided into the weight loss (WL) group $(n=6)$ and water-loading weight loss (WWL) group $(n=7)$. Wrestlers performed 2-week weight loss program targeting average of $5-10 \%$ of body weight reduction, under the supervision of a coach. Participants were instructed to drink 1.5-2 L and 6-7 L daily during the first week in the WL and WWL groups, respectively. Both groups were gradually reduced water intake and didn't drink water the day before weighing. Anthropometric characteristics, hematocrit (HCT), serum electrolytes, aldosterone, and cortisol were measured before and after weight loss. Data were analyzed with two-way ANOVA using SPSS. The significance level was set at $p<.05$.

RESULTS: After 2 weeks, the weight $(p=.004)$, BMI $(p<.001)$, lean body mass $(p<.001)$, body water composition $(p<.001)$, and SBP $(p=.046)$ were reduced significantly in both groups. However, there was no statistically significant between-group difference in all parameters of body composition and SBP. The HCT and chloride (Cl-) decreased in both WL and WWL groups $(p=.018$ and $p=.006$, respectively). Serum aldosterone and cortisol significantly increased in both groups $(p<.001)$. In particular, cortisol was significantly lower in theWWL than in WL group.

CONCLUSIONS: This study suggested that a large-volume hydration before water restriction for weight loss can be a safe method.

Key words: Water loading, Athletics, Wrestler, Weight loss, Cortisol

\section{INTRODUCTION}

Wrestling is a weight class-based sports. Wrestlers who often undergo weight loss to improve their performance and gain victories are interested in effective weight control. Entering a match with advantageous physical conditions is the main reason that drives many wrestlers to opt for weight loss prior to a match. This secures a relative physical advantage because they can select an opponent in a lower weight class, thereby reducing the psychological burden of having to face an opponent with similar skills and physique [1,2].

In general, athletes in weight class-based sports lose 5-10\% of their body weight before the match [3], and they usually attempt rapid rather than gradual weight loss. Increasing metabolism by reducing oral nutri- ent and fluid intake and increasing excretion are an option for rapid weight loss [4-6]. Although athletes adopt one or more of the various weight loss regimens, the regulation of oral nutrient intake and restriction of hydration are the most common strategy for weight loss. In particular, water restriction is the most frequently used option for weight loss 2-3 days before weight measurement [7].

Since water comprises $65 \%$ of the human body, dehydration or sweating is an effective method for temporary weight loss [7]. The normal body water composition can be achieved rapidly after weight measurement through hydration. Therefore, many athletes use dry or wet saunas, train in heated rooms, or restrict water intake in order to lose weight $[8,9]$. However, weight loss through the restriction of oral nutrient intake and dehydration has been reported to have negative effects such as a de-

Corresponding author: Taekyung Han Tel +82-54-820-5573 Fax +82-54-820-5823 E-mail hantkdanu.ac.kr

*This work was supported by the Ministry of Education of the Republic of Korea and National Research Foundation of Korea (NRF- 2019S1A5C2A03082727).

Received 31 Jul 2020 Accepted 25 Aug 2020

@)This is an Open Access article distributed under the terms of the Creative Commons Attribution Non-Commercial License (https://creativecommons.org/licenses/by-nc/4.0/) which permits unrestricted non-commercial use distribution, and reproduction in any medium, provided the original work is properly cited. 
crease in glycogen storage and decreased muscle strength and endurance through the loss of muscle tissue [10]. Furthermore, it causes a decrease in serum testosterone [11], electrolyte deficiency from extreme dehydration, and increased cardiac burden due to a decrease in blood volume. Finally, it upsets thermoregulation, decreases the kidney function such as the glomerular filtration rate [12] and exerts a negative psychological impact [13].

Effective weight loss in weight class-based sports should decrease physical and psychological stress during weight loss and minimize the decline in match proficiency through the adequate regulation of the physiological body composition and homeostasis. During weight loss, dehydration from water restriction rather than physical distress is the greatest source of stress for wrestlers. Hence, it can be deduced that a weight loss option that can minimize dehydration and maintain the homeostasis of water and heat would be most helpful. However, few studies have measured and confirmed this theory $[1,14,15]$.

The estimated average requirement of water in the healthy state varies greatly among individuals based on metabolism, physical activity, and the environment. The Third National Health and Nutrition Examination Survey (NHANES III) showed that the average water intake in United States adults is $3.7 \mathrm{~L} /$ day in males and $2.7 \mathrm{~L}$ /day in females, based on difference in water intake and water loss. NHANES III also reports that high-intensity physical activity required $7 \mathrm{~L}$ of water per day $[16,17]$. In other words, for athletes undergoing rapid stamina loss and high intensity training such as wrestlers, ample hydration on par with heat and energy expenditure is an indispensable factor in improving the match proficiency and ensuring a longer lifecycle as athletes. Therefore, weight control with adequate hydration in wrestlers who wish to lower their weight class before a match is necessary. Some fighters of the Ultimate Fighting Championship have adopted weight loss while maintaining adequate hydration; however, there is no scientific validation available for this method yet. Therefore, this study investigated the impact of waterloading weight loss on the body composition, serum electrolytes, body water regulation, and stress hormones in college wrestlers.

\section{METHODS}

\section{Participants}

This study was conducted on 13 male wrestlers enrolled in our university, who are all aiming for 5-10\% weight loss before the world championship. The 13 subjects were divided into weight loss group (WL, 6
Table 1. Characteristic subjects (mean \pm SD)

\begin{tabular}{lrr}
\hline Variables & WL $(n=6)$ & WWL $(n=7)$ \\
\hline Age $(\mathrm{yr})$ & $18.0 \pm 0.8$ & $18.0 \pm 0.6$ \\
Height $(\mathrm{cm})$ & $172.3 \pm 5.6$ & $171.5 \pm 4.1$ \\
Weight $(\mathrm{kg})$ & $71.3 \pm 7.9$ & $71.7 \pm 8.3$ \\
BMI $\left(\mathrm{kg} / \mathrm{m}^{2}\right)$ & $24.0 \pm 1.6$ & $24.5 \pm 2.2$ \\
Competition experience $(\mathrm{yr})$ & $8.0 \pm 1.1$ & $8.2 \pm 1.3$ \\
\hline
\end{tabular}

WL, weight loss group; WWL, water-loading weight loss group; BMI, body mass index.

subjects) and water-loading weight loss group (WWL, 7 subjects). Subjects had no prior medical history of cardiopulmonary, renal, or orthopedic disease, and were able to abstain from taking drugs, alcohol, and tobacco during the study period. The baseline characteristics of subject by group are shown in Table 1 .

\section{Study design}

We analyzed the body composition, water regulatory function, and serum electrolytes in each of the two groups. Subjects in the WL group were instructed to drink $1.5-2 \mathrm{~L}$ of water $(30 \mathrm{~mL} / \mathrm{kg})$ per day from 2 weeks prior to weighing and then conduct a weight loss program similar to the traditional method by restricting diet intake, water, and training. Subjects in the WWL were instructed to drink 6-7 L (100 mL/kg) per day from 2 weeks prior to weighing then undergo weight loss with nutrient intake restriction and gradual reduction of water intake. Both groups had no water intake the day before the weighing (Fig. 1).

\section{Body composition}

An automatic measurement system (BSM 330, Biospace, Korea) was used to measure the height and weight of each subject wearing the lightest possible outfit. An X-Scan Body Composition Analyzer (Jawon Medical Co., Seoul, Korea), which uses bioelectrical impedance analysis, was used to measure the body fat composition, lean body mass, and body water composition. An automatic blood pressure machine (JAWON Medical Co., Seoul, Korea) was used to measure blood pressure after 20 minutes of rest. The mean value of two measurements taken at intervals of 5 minutes was used for analysis.

\section{Blood analysis}

All subjects provided blood samples from the brachial vein 2 weeks before the start of the weight loss program and 20 minutes after the match. The samples were centrifuged at 3,000 rpm for 15 minutes. The plasma was separated and stored at $-80^{\circ} \mathrm{C}$ until the time of analysis. The 
No water intake (24hr)

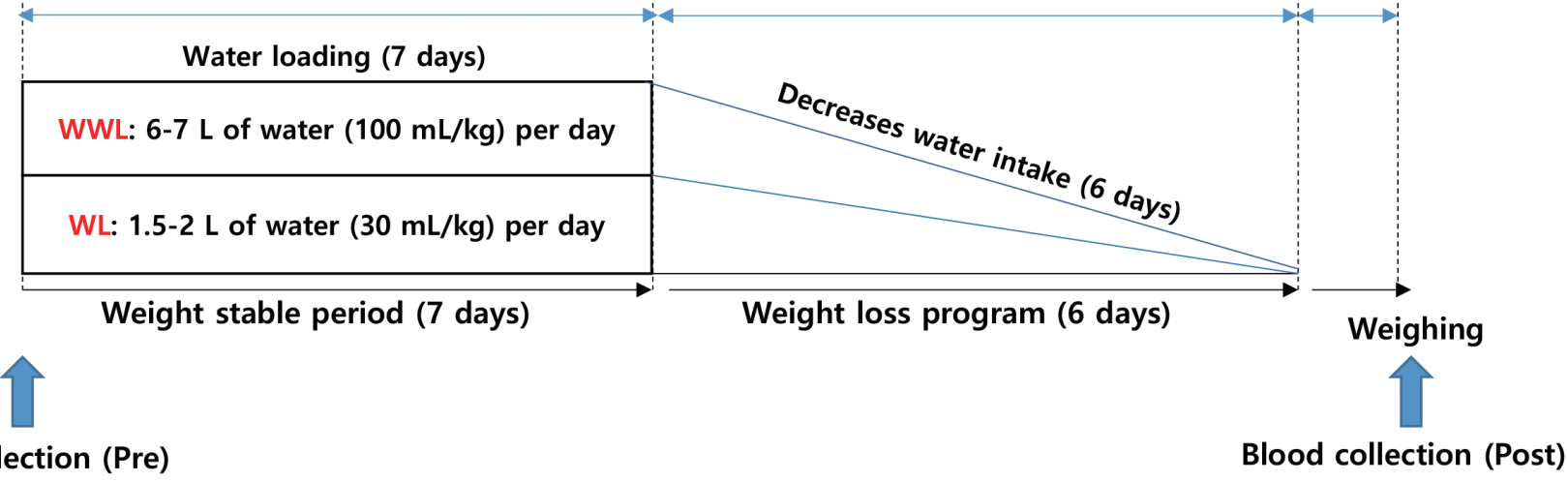

Blood collection (Pre)

Blood collection (Post)

Fig. 1. Study outline. WL, weight loss; WWL, water-loading weight loss.

plasma sodium $\left(\mathrm{Na}^{+}\right)$, potassium $\left(\mathrm{K}^{+}\right)$, calcium $\left(\mathrm{Ca}^{2+}\right)$, and chloride $\left(\mathrm{Cl}^{-}\right)$ were measured using ion-specific electrodes. The plasma aldosterone and cortisol concentrations were measured using radioimmuno assay (Quantum, USA), and hemoglobin concentration and hematocrit (HCT) were analyzed using an automatic blood analysis system (SYSMEX, XE2100, Japan).

\section{Data analysis}

All measurable variables were expressed as the mean and standard deviation. The difference between the two groups in the change in body composition and serum markers was tested for statistical significance using the two-way ANOVA with repeated measure. All statistical analyses were conducted using the SPSS-PC version 18.0, and significance level was defined was $\alpha=.05$.

\section{RESULTS}

\section{Baseline characteristics}

The average age of the subjects was $18.0 \pm 0.8$ years in the WL group, and $18.0 \pm 0.6$ years in the WWL group, showing no significant difference between the groups. There were no statistically significant differences in the baseline characteristics between the two groups, including height, weight, body mass index (BMI), and competition experience (Table 1).

\section{Change in body composition and blood pressure}

Table 2 shows the data before and after the intervention on body composition and blood pressure. After 2 weeks of intervention, the weight was reduced by $8.2 \%$ from $71.3 \pm 7.9 \mathrm{~g}$ to $65.4 \pm 8.8 \mathrm{~g}$ in the WL group and
Table 2. Change of body composition and blood pressure (mean \pm SD)

\begin{tabular}{llccc}
\hline Variable & Group & Pre & Post & $p$-value \\
\hline Weight (g) & WL & $71.3 \pm 7.9$ & $65.4 \pm 8.8$ & $\mathrm{a}=.004$ \\
& WWL & $71.7 \pm 8.3$ & $63.7 \pm 7.3$ & $\mathrm{~b}=.884$ \\
& & & & $\mathrm{c}=.590$ \\
BMI (kg/m²) & WL & $24.0 \pm 1.6$ & $22.0 \pm 1.6$ & $\mathrm{a}<.001$ \\
& WWL & $25.6 \pm 2.2$ & $22.5 \pm 1.6$ & $\mathrm{~b}=.271$ \\
& & & & $\mathrm{c}=.195$ \\
Lean body mass (kg) & WL & $57.5 \pm 6.1$ & $53.2 \pm 4.8$ & $\mathrm{a}<.001$ \\
& WWL & $57.8 \pm 6.5$ & $51.3 \pm 4.8$ & $\mathrm{~b}=.797$ \\
& & & & $\mathrm{c}=.326$ \\
Total body water (L) & WL & $45.3 \pm 4.9$ & $41.1 \pm 3.8$ & $\mathrm{a}<.001$ \\
& WWL & $45.4 \pm 5.1$ & $39.6 \pm 3.7$ & $\mathrm{~b}=.786$ \\
& & & & $\mathrm{c}=.339$ \\
Percent body fat (\%) & WL & $12.8 \pm 2.5$ & $12.4 \pm 4.9$ & $\mathrm{a}=.803$ \\
& WWL & $13.6 \pm 1.5$ & $13.3 \pm 5.3$ & $\mathrm{~b}=.570$ \\
& & & & $\mathrm{c}=.985$ \\
SBP (mmHg) & WL & $123.3 \pm 4.2$ & $117.0 \pm 13.0$ & $\mathrm{a}=.046$ \\
& WWL & $124.3 \pm 8.1$ & $117.6 \pm 7.9$ & $\mathrm{~b}=.849$ \\
& & & & $\mathrm{c}=.949$ \\
DBP (mmHg) & WL & $68.7 \pm 3.7$ & $63.0 \pm 7.5$ & $\mathrm{a}=.349$ \\
& WWL & $67.4 \pm 5.6$ & $68.0 \pm 7.2$ & $\mathrm{~b}=.422$ \\
& & & & $\mathrm{c}=.256$ \\
HR (bpm) & WL & $54.1 \pm 12.1$ & $57.8 \pm 10.5$ & $\mathrm{a}=.043$ \\
& WWL & $61.6 \pm 11.6$ & $64.0 \pm 3.6$ & $\mathrm{~b}=.542$ \\
& & & & $\mathrm{c}=.836$ \\
\hline
\end{tabular}

a, time. b, group. c, time $\times$ group.

$\mathrm{WL}$, weight loss group; WWL, water-loading weight loss group; BMI, body mass index; SBP, systolic blood pressure; DBP, distolic blood pressure; HR, heart rate.

by $11 \%$ from $71.7 \pm 8.3 \mathrm{~g}$ to $63.7 \pm 7.3 \mathrm{~g}$ in the WWL group, showing significant reductions in weight in both groups $(p=.004)$. Both the WL and WWL groups showed significant reduction in BMI $(p<.001)$, lean body mass $(p<.001)$, and body water composition $(p<.001)$. Moreover, both groups showed a significant reduction in the systolic blood pressure $(\mathrm{SBP})(p=.046)$ and a significant increase in the heart rate $(\mathrm{HR})(p=$ 
Table 3. Change of blood chemistry (mean \pm SD)

\begin{tabular}{llccc}
\hline Variable & Group & \multicolumn{1}{c}{ Pre } & Post & $p$-value \\
\hline $\mathrm{Hb}(\mathrm{g} / \%)$ & WL & $16.1 \pm 1.1$ & $15.6 \pm 2.9$ & $\mathrm{a}=.437$ \\
& WWL & $15.7 \pm 0.8$ & $15.0 \pm 1.8$ & $\mathrm{~b}=.515$ \\
$\mathrm{HCT}(\%)$ & $\mathrm{WL}$ & $51.1 \pm 2.8$ & $45.7 \pm 8.6$ & $\mathrm{a}=.018$ \\
& WWL & $49.7 \pm 2.3$ & $43.2 \pm 4.5$ & $\mathrm{~b}=.316$ \\
& & & & $\mathrm{c}=.807$ \\
$\mathrm{Ca}^{2+}(\mathrm{mEq} / \mathrm{L})$ & $\mathrm{WL}$ & $9.7 \pm 2.5$ & $9.5 \pm 0.2$ & $\mathrm{a}=.220$ \\
& WWL & $9.8 \pm 0.2$ & $8.6 \pm 2.5$ & $\mathrm{~b}=.505$ \\
& & & & $\mathrm{c}=.403$ \\
$\mathrm{Cl}^{-}(\mathrm{mEq} / \mathrm{L})$ & $\mathrm{WL}$ & $101.3 \pm 1.5$ & $98.5 \pm 2.0$ & $\mathrm{a}=.006$ \\
& $\mathrm{WWL}$ & $100.4 \pm 1.5$ & $99.0 \pm 3.6$ & $\mathrm{~b}=.863$ \\
& & & & $\mathrm{c}=.281$ \\
$\mathrm{Na}^{+}(\mathrm{mEq} / \mathrm{L})$ & $\mathrm{WL}$ & $141.0 \pm 1.3$ & $140.5 \pm 2.6$ & $\mathrm{a}=.469$ \\
& $\mathrm{WWL}$ & $141.3 \pm 0.8$ & $141.0 \pm 2.5$ & $\mathrm{~b}=.681$ \\
& & & & $\mathrm{c}=.842$ \\
$\mathrm{~K}^{+}(\mathrm{mEq} / \mathrm{L})$ & $\mathrm{WL}$ & $4.5 \pm 0.3$ & $3.7 \pm 0.2$ & $\mathrm{a}=.328$ \\
& $\mathrm{WWL}$ & $4.4 \pm 0.3$ & $4.6 \pm 1.8$ & $\mathrm{~b}=.212$ \\
& & & & $\mathrm{c}=.346$ \\
\hline
\end{tabular}

a, time. b, group. c, time $\times$ group.

WL, weight loss group; WWL, water-loading weight loss group; $\mathrm{Hb}$, hemoglobin; $\mathrm{HCT}$, hematocrit; $\mathrm{Ca}$, calcium; $\mathrm{Cl}$, chloride; $\mathrm{K}$, potassium.

.043)(Table 2). However, there was no statistically significant difference in all parameters of body composition and blood pressure between the two groups before and after the intervention.

\section{Change in blood markers}

Table 3 shows the change in blood markers after 2 weeks of weight loss. After 2 weeks of intervention, the HCT and Cl- in both WL and WWL groups showed a decrease ( $p=.018$ and $p=.006$, respectively); however, the main effect as well as the interaction before and after the intervention between the two groups did not show any significant changes (Table 3). Serum aldosterone significantly increased from before to after the intervention $(p<.001)$ (Fig. 2). Serum cortisol significantly increased from before to after the intervention $(p<.001)$, and the main effect as well as the interaction before and after the intervention between the two groups showed a statistically significant improvement (Fig. 3).

\section{DISCUSSION}

This was an interventional study comparing water-loading and waterrestricting weight loss programs with equal oral nutrient intake restrictions and physical training. We aimed to explore whether WWL is a safe and effective method for weight loss in athletes in weight class-based sports. After 2 weeks of a weight loss intervention, both the WL and

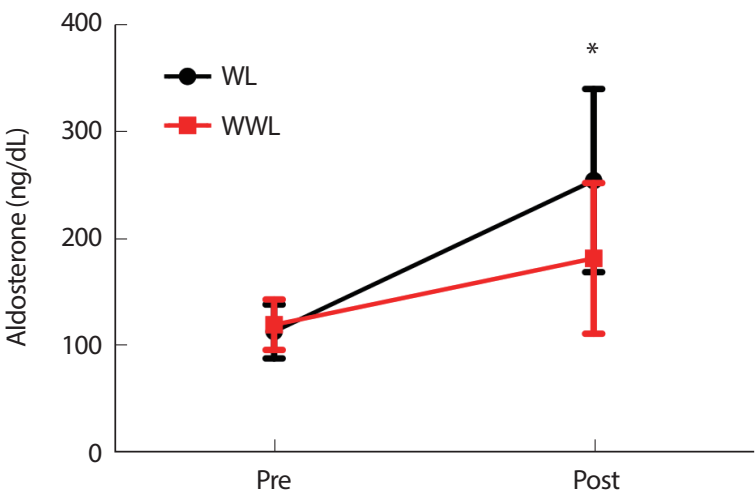

Fig. 2. Changes in aldosterone response following a 2-week intervention. WL, weight loss; WWL, water-loading weight loss. *significant change compared to the previous time point.

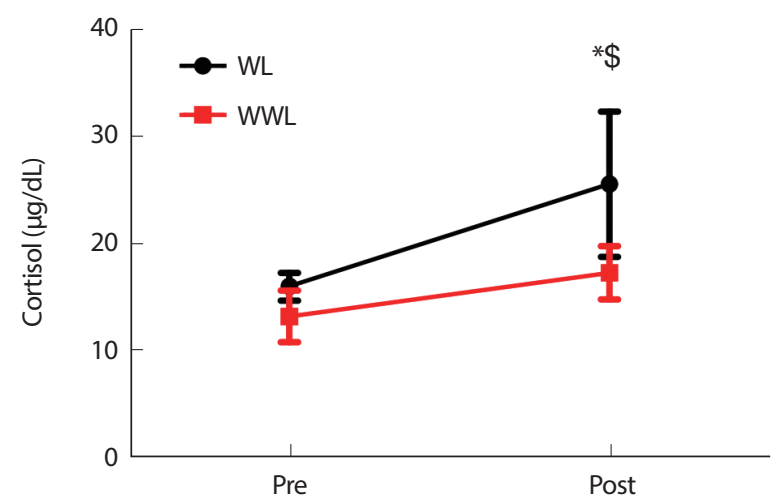

Fig. 3. Changes in cortisol response following a 2-week intervention. Timeby-group interaction effects were $p<.05$. WL, weight loss; WWL, waterloading weight loss. *significant change compared to the previous time point. \$, significant difference between groups.

WWL groups reached their target weights, showed a reduced serum $\mathrm{HCT}$ and $\mathrm{Cl}-$, and increased serum aldosterone and cortisol. In particular, the WWL group showed a significantly smaller rate of increase in cortisol level compared to the WL group.

This study utilized programs consisting of water and energy restriction with high-intensity training for weight loss. As a result, the WL and WWL groups showed a weight loss of $8.2 \%$ and $11 \%$, respectively. A previous study showed that water loading followed by weight loss with water restriction led to a greater urine production during both the waterloading and water-restriction phases compared to those of the control group. This continuous diuresis was shown to increase excretion and induce weight loss. As in our study, this led to the conclusion that water loading is an effective method for weight loss [18].

We also showed a decrease in lean body weight following weight loss, probably due to restriction of oral nutrient intake coupled with high-in- 
tensity training during the weight loss program. This most likely led to negative changes in the body composition such as a decrease the fat and lean body masses due to a depletion of glycogen storage. Since wrestlers maintain a low body fat content with intensive training, excessive food restriction over a short period would have played a role in decreasing the lean body mass [19]. An adequate weight control is necessary inasmuch as changes in the body composition after weight loss, i.e., a decreased lean body mass, are reported to decrease muscle strength, endurance, and aerobic exercise capacity leading to a decreased match proficiency [20].

On the other hand, WL was shown to decrease the SBP and HR. Both groups showed a decreased SBP, which was contrary to the previous findings in which electrolyte imbalance from dehydration increased cardiac load $[1,10]$. This is probably due to an adequate hydration after the competition resulting in the stabilization of the SBP and HR, which must be understood collectively with electrolytes and aldosterone. In order to preserve water during exercise, the sympatheto-adrenal system secretes catecholamines that cause arteriole constriction in the glomerulus and decreased blood flow to the kidneys [20]. This can decrease urine output by $50 \%$. However, the physiological water conservation is inadequate to replenish water loss that occurs during exercise [20]. This study tested the WWL method that allows for ample hydration during the weight loss period, which showed a weight loss effect on par with the traditional weight loss method as well as electrolyte levels. This study did not show significant changes in $\mathrm{Na}^{+}$and $\mathrm{K}^{+}$in both groups, which achieved approximately $10 \%$ weight loss. In other words, the increased demand in stimulation frequency due to increased core body and muscle temperatures from dehydration, rather than water metabolism imbalance, seems to be the mechanism behind the decreased muscle endurance from dehydration [22-24].

According to recent studies, excessive water intake can cause hyponatremia [25], and excessive hydration can be dangerous as a rapid decrease in serum sodium levels can lead to death $[25,26]$. Previous studies have reported the risk of hyponatremia within 6 hours associated with the intake of more than $10 \mathrm{~L}$ of water, or greater fluid intake compared to fluid excretion $[25,26]$. In this study, subjects were instructed to drink 6-7 L of water per day for 1 week prior to water restriction, which did not lead to significant changes in serum electrolytes. Hence, we can conclude that hydration of 6-7 L per day does not cause hyponatremia. Serum aldosterone, a hormone that regulates body water, was significantly increased after weight loss, and the WWL group showed a greater increase compared to the WL group. Aldosterone is a hormone released from the ad- renal cortex that regulates the sodium concentration by playing a role in sodium and potassium homeostasis. Dehydration from rapid weight loss can lead to a decrease in plasma volume, blood pressure, sodium, and potassium. To maintain homeostasis under these physiological changes, the renin-angiotensin system is activated to induce the reabsorption of sodium and water [27]. This study revealed that the WWL group showed a lower aldosterone level compared to the WL group, which signifies a more efficient water regulation despite higher degrees of weight loss. In other words, the WWL is more efficient and can lead to water regulation in the kidneys.

This study also showed that serum cortisol levels increased in both groups. Previous studies reported that cortisol levels increased immediately after exercise or with a greater intensity and longer duration of exercise [28-30]. Other previous studies have shown that a reduced carbohydrate intake and the resultant undernutrition from starvation also increases serum cortisol [31] and that a decrease in the anti-inflammatory response or stress due to rapid weight loss can also increase stress hormones such as cortisol [32]. The change in hormone levels after exercise is reported to depend on multiple factors such as the training status of individuals, exercise load, duration of exercise, body composition, and psychological state [33]. In this study, a rise in serum cortisol was seen after weight loss. It was also shown that the WWL group had a significantly smaller increase in cortisol compared to the WL group. In other words, while both groups showed an increased serum cortisol due to water and food restriction and high intensity training, water loading prior to water restriction showed an alleviation of the stress of dehydration.

However, this study has a few limitations. As this study observes body compositions and hematological markers before and after weight loss, it does not provide insight into change during weight loss. Since blood samples were obtained after 20 minutes of rest following a match, during which water absorption takes place, this study did not observe the prehydration state immediately after weight loss. Furthermore, it did not show the difference in physical function between the different methods of weight loss. Therefore, there is a need for future studies that can specify the safety and efficacy of weight loss with hydration by observing the physical strength or match proficiency.

\section{CONCLUSIONS}

With weight loss in wrestlers, both the WL and WWL groups showed a decreased body weight, BMI, body fat, body water, and SBP, a signifi- 
cantly increased HR at rest. Serum HCT and Cl- decreased, while serum aldosterone and cortisol increased in both groups after weight loss. In particular, cortisol, a stress hormone, was significantly lower in the WWL than in WL group. This implies that large-volume hydration before water restriction for short-term weight loss is a safe method. However, future studies are needed to further clarify the effect of weight loss on physical strength and match proficiency.

\section{CONFLICT OF INTEREST}

No potential conflict of interest relevant to this article was reported.

\section{AUTHOR CONTRIBUTIONS}

Conceptualization: J Cho, T Han; Data curation: T Han; Funding acquisition: J Cho; Methodology: T Han; Project administration: T Han; Writing-original draft: J Cho; Writing-review \& editing: T Han.

\section{ORCID}

Taekyung Han https:/orcid.org/0000-0003-0759-3454

Jinkyung Cho https://orcid.org/0000-0002-4500-3622

\section{REFERENCES}

1. Kim GJ. Changes of blood electrolytes and body composition after rapid weight loss through dehydration and caloric restriction. Journal of Exercise Nutrition \& Biochemistry. 2003;7(1):55-62.

2. Khodaee M, Olewinski L, Shadgan B, Kiningham RR. Rapid weight loss in sports with weight classes. Curr Sports Med Rep. 2015;14(6): $435-41$.

3. Steen SN, Brownell KD. Patterns of weight loss and regain in wrestlers: has the tradition changed? Med Sci Sports Exerc. 1990;22(6):762-8.

4. Artioli GG, Gualano B, Franchini E, Scagliusi FB, Takesian M, et al. Prevalence, magnitude, and methods of rapid weight loss among judo competitors. Med Sci Sports Exerc. 2010;42(3):436-42.

5. Turocy PS, DePalma BF, Horswill CA, Laquale KM, Martin TJ, et al. National Athletic Trainers' Association. National Athletic Trainers' Association position statement: safe weight loss and maintenance practices in sport and exercise. J Athl Train. 2011;46(3):322-36.

6. Kiningham RB, Gorenflo DW. Weight loss methods of high school wrestlers. Med Sci Sports Exerc. 2001;33(5):810-3.

7. Morton JP, Robertson C, Sutton L, MacLaren DP. Making the weight: a case study from professional boxing. Int J Sport Nutr Exerc Metab. 2010;20(1):80-5.

8. Oppliger RA, Steen SA, Scott JR. Weight loss practices of college wrestlers. Int J Sport Nutr Exerc Metab. 2003;13(1):29-46.

9. Oppliger RA, Case HS, Horswill CA, Landry GL, Shelter AC. American College of Sports Medicine position stand. weight loss in wrestlers. Med Sci Sports Exerc. 1996;28(6):ix-xii.

10. Houston ME, Marrin DA, Green HJ, Thomson JA. (1981). The effect of rapid weight loss on physiological functions in wrestlers. Phys Sportsmed. 1981;9(11):73-8.

11. Karila TA, Sarkkinen P, Marttinen M, Seppälä T, Mero A, et al. Rapid weight loss decreases serum testosterone. Int J Sports Med. 2008;29(11): 872-7.

12. Caldwell JE, Ahoene E, Nousiainen U. Differential effects of sauna-, diuretic-, and exercise-induced hypohydration. J Appl Physiol Respir Environ Exerc Physiol. 1984;57(4):1018-23.

13. Sundgot-Borgen J, Garthe I. Elite athletes in aesthetic and olympic weight-class sports and the challenge of body weight and body compositions. J Sports Sci. 2011;29 Suppl 1:S101-14.

14. Yang SH. Effects of short-term weight Loss on stress hormone and immune function in Judo players. Exercise Science. 2010;19(3):289300.

15. Oh MJ, Kang SH, Kim JO, Seo TB, Kim JJ, et al. The effects of acute weight loss on body water balance and Lipid peroxidation index in collegiate wrestling athletes. The Korean Journal of Physical Education. 2007;46(3):453-60.

16. Sawka MN, Montain SJ. Fluid and electrolyte supplementation for exercise heat stress. Am J Clin Nutr. 2000;72(2 Suppl):564S-72S.

17. Ruby BC, Shriver TC, Zderic TW, Sharkey BJ, Burks C, et al. Total energy expenditure during arduous wildfire suppression. Med Sci Sports Exerc. 2002;34(6):1048-54.

18. Reale R, Slater G, Cox GR, Dunican IC, Burke LM. The effect of water loading on acute weight loss following fluid restriction in combat Sports Athletes. Int J Sport Nutr Exerc Metab. 2018;28(6):565-73.

19. Kim ES, Jang MJ, Lee MG, Jang WS. Effects of short-term weight loss on physical fitness level and blood variables. Exercise Science. 2002; 11(2):555-62.

20. Reale R, Slater G, Burke LM. Acute-weight-loss strategies for combat sports and applications to olympic success. Int J Sports Physiol Per- 
form. 2017;12(2):142-51.

21. Baer PG, McGiff JC. Hormonal systems and renal hemodynamics. Annu Rev Physiol. 1980;42:589-601.

22. Viitasalo JT, Kyrolainen H, Bosco C, Alen M. Effects of rapid weight reduction on force production and vertical jumping height. Int J Sports Med. 1987;8(4):281-5.

23. Rome LC, Kushmerick MJ. Energetics of isometric contractions as a function of muscle temperature. Am J Physiol. 1983;244(1):C100-9.

24. Segal SS, Faulkner JA, White TP. Skeletal muscle fatigue in vitro is temperature dependent. J Appl Physiol (1985). 1986;61(2):660-5.

25. Adrogué HJ, Madias NE. Hyponatremia. N Engl J Med. 2000;342(21): $1581-9$.

26. Garigan TP, Ristedt DE. Death from hyponatremia as a result of acute water intoxication in an Army basic trainee. Mil Med. 1999;164(3): 234-8.

27. Engeli S, Böhnke J, Gorzelniak K, Janke J, Schling P, et al. Weight loss and the renin-angiotensin-aldosterone system. Hypertension. 2005; 45(3):356-62.

28. Degoutte F, Jouanel P, Bègue RJ, Colombier M, Lac G, et al. Food re- striction, performance, biochemical, psychological, and endocrine changes in judo athletes. Int J Sports Med. 2006;27(1):9-18.

29. Abedelmalek S, Chtourou H, Souissi N, Tabka Z. Caloric restriction effect on proinflammatory cytokines, growth hormone, and steroid hormone concentrations during exercise in judokas. Oxid Med Cell Longev. 2015;2015:809492.

30. Maresh CM, Whittlesey MJ, Armstrong LE, Yamamoto LM, Judelson DA, et al. Effect of hydration state on testosterone and cortisol responses to training-intensity exercise in collegiate runners. Int J Sports Med. 2006;27(10):765-70.

31. Anderson RA, Bryden NA, Polansky MM, Thorp JW. Effects of carbohydrate loading and underwater exercise on circulating cortisol, insulin and urinary losses of chromium and zinc. Eur J Appl Physiol Occup Physiol. 1991;63(2):146-50.

32. Pedersen BK, Hoffman-Goetz L. Exercise and the immune system: regulation, integration, and adaptation. Physiol Rev. 2000;80(3):1055-81.

33. Stallknecht B, Kjaer M, Mikines KJ, Maroun L, Ploug T, et al. Diminished epinephrine response to hypoglycemia despite enlarged adrenal medulla in trained rats. Am J Physiol. 1990;259(5 Pt 2):R998-1003. 